Check for updates

Cite this: RSC Adv., 2018, 8, 28944

\title{
Carboxymethylcellulose ammonium-derived nitrogen-doped carbon fiber/molybdenum disulfide hybrids for high-performance supercapacitor electrodes $\dagger$
}

\begin{abstract}
Yanyan Lv, ${ }^{a}$ Yi Zhou, (D) ${ }^{a}$ Ziqiang Shao, (D) *a Jie Wei, ${ }^{a}$ Lei Li (D) a and Yiping Wang ${ }^{b}$
In this paper, a new type of nitrogen-doped carbon fiber/molybdenum disulfide (N-CFs/MoS 2 ) hybrid electrode materials are prepared via a certain concentration in solvothermal synthesis followed by a high-temperature carbonization process and using the carboxymethylcellulose ammonium $\left(\mathrm{CMC}-\mathrm{NH}_{4}\right)$ as a structure-directing agent for $\mathrm{MOS}_{2}$ nanosheet growth during the solvothermal synthesis process. The addition of $\mathrm{CMC}_{-} \mathrm{NH}_{4}$ effectively prevents the agglomeration of $\mathrm{MOS}_{2}$ nanosheets to increase the specific surface area. Moreover, it not only serves as a carbon source to provide conductive pathways, but also introduces $\mathrm{N}$ atoms to improve the conductivity of the CFs and promote the transfer of electrons and ions. This ultimately increases the conductivity of the electrode materials. Thus, the asprepared $\mathrm{N}-\mathrm{CFs} / \mathrm{MoS}_{2}$ hybrids exhibit excellent electrochemical performance. The specific capacitance is up to $572.6 \mathrm{~F} \mathrm{~g}^{-1}$ under a current density of $0.75 \mathrm{~A} \mathrm{~g}^{-1}$ and the specific capacitance retained $98 \%$ of the initial capacitance after 5000 cycles of charge-discharge tests at a current density of $2.5 \mathrm{~A} \mathrm{~g}^{-1}$. Moreover, the hybrids show a maximum energy density of $19.5 \mathrm{~W} \mathrm{~h} \mathrm{~kg}^{-1}$ at a power density of $94 \mathrm{~W} \mathrm{~kg}^{-1}$. Therefore, the as-prepared N-CFs/MoS 2 hybrids with remarkable electrochemical properties, low cost and environment protection show potential for practical application in the development of high-performance electrochemical energy storage devices.
\end{abstract}

Received 25th May 2018

Accepted 6th August 2018

DOI: $10.1039 / c 8 r a 04492 a$

rsc.li/rsc-advances

\section{Introduction}

The diminishing reserves of non-renewable fossil fuels and the changing global climate have led to efforts to find sustainable, renewable energy and conversion and storage devices that possess the advantages of high efficiency, environmental friendliness and reutilization. ${ }^{1-3}$ Lithium-ion batteries and supercapacitors are the two common energy systems with excellent performance of high-capacity and fast charge/ discharge rates., ${ }^{\mathbf{4} 5}$ As one kind of important electrochemical energy storage device, supercapacitors with high power density, low cost, high reliability, environment-friendly and long life and other advantages have aroused people's widespread interest with the rapid development of electric vehicles, clean energy storage and other electronic products. ${ }^{\mathbf{6}-10}$ Their performance mainly relies on physicochemical processes at the electrode-

${ }^{a}$ Beijing Engineering Research Centre of Cellulose and Its Derivatives, School of Materials Science and Engineering, Beijing Institute of Technology, Beijing, 100081, P. R. China.E-mail: shaoziqiang@263.net

${ }^{b}$ Nantong Tailida Chemical Co., Ltd, Jiangsu, 226000, P. R. China

$\dagger$ Electronic supplementary information (ESI) available: The SEM images of CMC-NH $\mathrm{NH}_{4}$ and $\mathrm{CMC}-\mathrm{NH}_{4} / \mathrm{MoS}_{2}$ prepared via solvothermal synthesis under ethanol solutions with different concentrations, and the calculation formula of the electrochemical parameters. See DOI: 10.1039/c8ra04492a electrolyte interface such as ion transfer, charge transfer and electrodes wetted by electrolyte. Therefore, electrode materials are one of the main factors that affect the electrochemical performance of the supercapacitor and the current research focus is mainly on the electrode material with excellent electrochemical properties and appropriate microstructure. ${ }^{\mathbf{1 1 - 1 3}}$

As a typical 2D transition metal dichalcogenides (TMDs) layered material, molybdenum disulfide $\left(\mathrm{MoS}_{2}\right)$ shows graphene-like structure and has a layered structure held together by weak van der Waals forces, and in which molybdenum atoms are sandwiched between two layers of sulfur atoms. Its researches on energy storage devices have achieved improved interest in recent years because of they can provide high specific surface area for charge storage of electric double layer. ${ }^{\mathbf{1 4 , 1 5}}$ However, it is reported that the $\mathrm{MoS}_{2}$ electrode can exhibit a fast capacity decaying and inferior rate capability during charge-discharge cycling because of its large volume change and poor electrical/ionic conductivity between the two adjacent S-Mo-S sheets. ${ }^{\mathbf{1 6 - 1 8}}$ Moreover, during the synthesis, the $\mathrm{MoS}_{2}$ nanosheets can grow and self-assemble together ascribe to its 2D structure. Consequently, hybridization of $\mathrm{MoS}_{2}$ with other conductive materials to form hierarchical nanostructures is an effective method to improve the dispersion of $\mathrm{MoS}_{2}$ nanosheets and enhance its conductivity to achieve optimal 
specific capacitance. Currently, $\mathrm{MoS}_{2}$-based hybrids such as $\mathrm{MoS}_{2} / \mathrm{RGO}, \mathrm{MoS}_{2} / \mathrm{PANI}, \mathrm{MoS}_{2} /$ carbon fibers, and cellulose nanofibers/ $\mathrm{MoS}_{2} / \mathrm{RGO}$ as electrode materials for supercapacitors have been reported in the articles. ${ }^{19-22}$ Although the hybrids' electrochemical performances are not poor, the substrates are not environmentally friendly and renewable.

Cellulose ether is an important cellulose derivative. ${ }^{23}$ It is the generic terms of a variety of derivatives obtained after alkalization, etherification, purification and drying the natural cellulose which as raw material and it is widely used in many fields such as agriculture, industry, daily chemical industry, aerospace and defence, environmental protection, biomedicine, nanomaterials, optoelectronic materials and so on for its abundant resource, low cost, and eco-friendliness. Carboxymethylcellulose ammonium $\left(\mathrm{CMC}-\mathrm{NH}_{4}\right)$ is a kind of ionic cellulose ether which can easily dissolve in water for it has a number of ammonium carboxymethyl groups $\left(-\mathrm{CH}_{2}-\right.$ $\mathrm{COONH}_{4}$ ). Using it as a carbon source can obtain nitrogendoped carbon fibers (N-CFs) by high-temperature carbonization process. The introduction of nitrogen atoms can effectively enhance the electron-donating ability of the surface of carbon material and reduce the valence orbital energy levels to induce synergistically enhanced conductive capacity. ${ }^{\mathbf{2 4}}$

A novel, low-cost and environmentally friendly N-CFs/MoS hybrids are successfully prepared via solvothermal synthesis followed by a high-temperature carbonization process (Fig. 1). The CMC- $\mathrm{NH}_{4}$ serves as a structure-directing agent in the solvothermal synthesis of $\mathrm{MoS}_{2}$ nanosheets. However, $\mathrm{CMC}-\mathrm{NH}_{4}$ is a water-soluble cellulose ether that contains many ammonium groups $\left(-\mathrm{CH}_{2} \mathrm{COONH}_{4}\right)$. It maintains its molecular form when dissolved in water, but it is insoluble in anhydrous ethanol.
Therefore, ethanol aqueous solution with certain concentration is first prepared, so that the $\mathrm{CMC}-\mathrm{NH}_{4}$ is slowly released into the aqueous medium and still exists as fibers forms. It thus can serve as a structure-directing agent for the growth of $\mathrm{MoS}_{2}$ nanosheets during the solvothermal synthesis process. The addition of $\mathrm{CMC}^{-\mathrm{NH}_{4}}$ effectively prevents the self-assembly agglomeration of the $\mathrm{MoS}_{2}$ nanosheets and thus helps to increase the specific surface area of $\mathrm{MoS}_{2}$, which further provides large numbers of active sites for electrochemical reactions, offers more contact area for electrolyte and electrode materials, and reduces the distance for ion diffusion. Moreover, it not only serves as a carbon source to provide conductive pathways, but also introduces $\mathrm{N}$ atoms to effectively improve the electron-donating ability of the carbon material from its surface, lower the valence orbital energy, and ultimately improve the conductivity of the electrode materials. The asprepared low-cost electrode materials not only exhibit excellent electrochemical performance but also are environmentally friendly, making it a candidate for practical applications in the energy field.

\section{Experimental}

\section{Materials}

CMC- $-\mathrm{NH}_{4}$, with a degree of substitution of 0.9 , was purchased from Beijing North Century Cellulose Technology Research\&Development Co., Ltd. Ethanol (EtOH), sodium molybdate $\left(\mathrm{Na}_{2} \mathrm{MoO}_{4} \cdot 2 \mathrm{H}_{2} \mathrm{O}\right)$, L-cysteine, potassium hydroxide $(\mathrm{KOH})$ and $\mathrm{N}$-methylpyrrolidone (NMP) were analytic grade and purchased from Sinopharm Chemical Reagent Beijing Co., Ltd. Polyvinylidene fluoride (PVDF) was provided by Sigma-Aldrich, Co.,

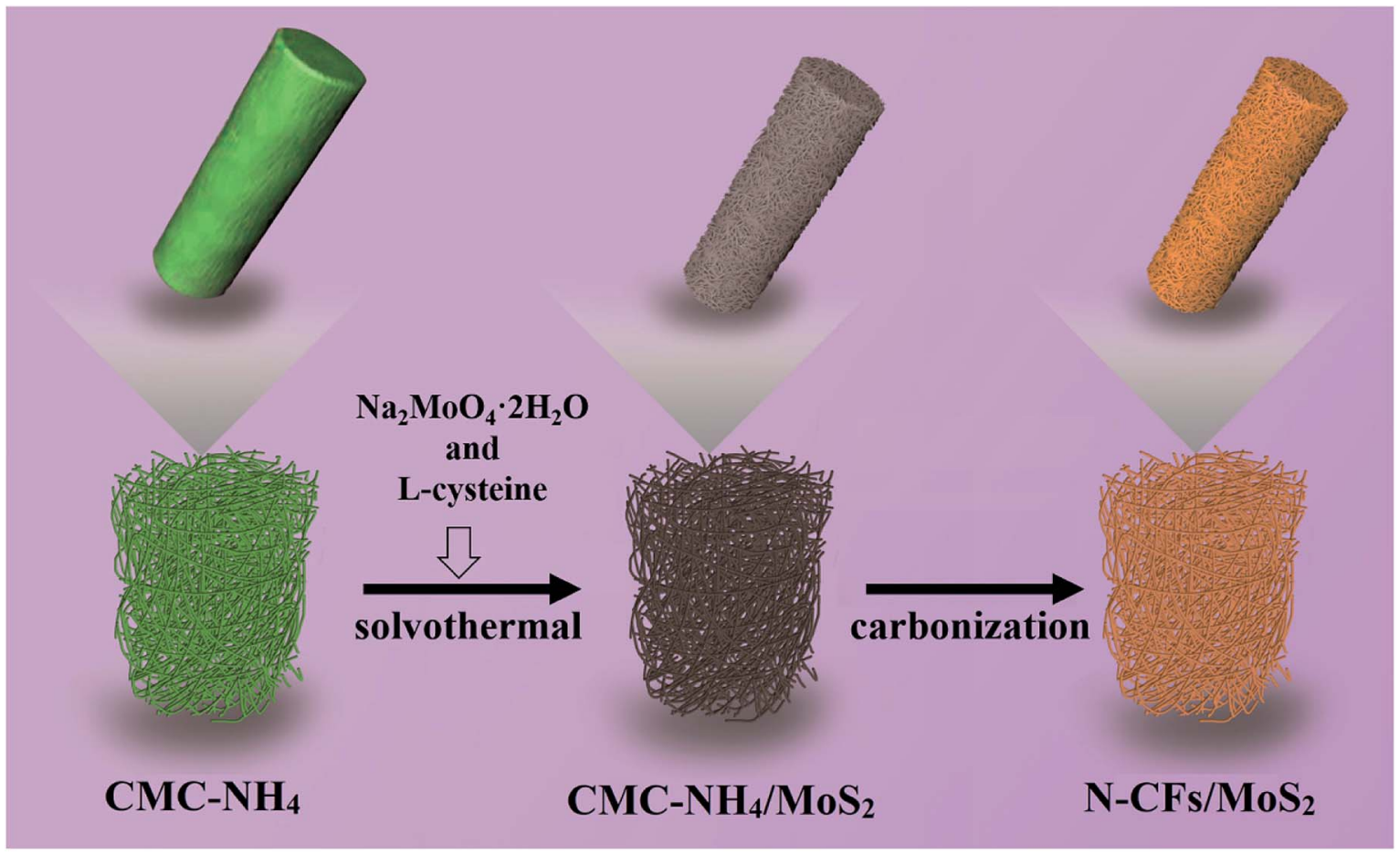

Fig. 1 Diagrammatic sketch of the preparation process of the $\mathrm{N}-\mathrm{CFs} / \mathrm{MoS}_{2}$ hybrid electrode materials. 
Ltd. Acetylene black and nickel foam were obtained from Changsha Liyuan New Material Co., Ltd.

\section{Preparation of $\mathrm{CMC}-\mathrm{NH}_{4} / \mathrm{MoS}_{2}$ hybrid materials}

Ethanol aqueous solutions (70 g) of different concentrations $(0 \%, 25 \%, 50 \%, 75 \%$, and $100 \%)$ were first prepared, after which the CMC-NH $\mathrm{CH}_{4}(0.4 \mathrm{~g})$ was magnetically stirred for $6 \mathrm{~h}$ and dispersed in the above solutions. Then, $\mathrm{Na}_{2} \mathrm{MoO}_{4} \cdot 2 \mathrm{H}_{2} \mathrm{O}(0.4 \mathrm{~g})$ was magnetically stirred and ultrasonically dispersed in the dispersions. L-cysteine ( $1 \mathrm{~g}$ ) was added via magnetic stirring and ultrasonic dispersion. The as-prepared dispersions were then transferred into a $100 \mathrm{~mL}$ Teflon-lined stainless-steel autoclave and heated at $200{ }^{\circ} \mathrm{C}$ for $24 \mathrm{~h}$. After cooling naturally, the black CMC-NH $4 / \mathrm{MoS}_{2}$ hybrid materials were collected by filtration, washed with $85 \%$ ethanol solutions three to five times and cleaned with anhydrous ethanol, and then dried under vacuum at $60{ }^{\circ} \mathrm{C}$ for $24 \mathrm{~h}$. For comparison, pure $\mathrm{MoS}_{2}$ powder was prepared via hydrothermal synthesis in a similar way.

\section{Preparation of N-CFs/MoS $/ \mathrm{M}_{2}$ hybrid electrode materials}

The above-prepared $\mathrm{CMC}-\mathrm{NH}_{4} / \mathrm{MoS}_{2}$ hybrid materials were carbonized in a tube furnace under flowing nitrogen atmosphere at a constant temperature of $800{ }^{\circ} \mathrm{C}$ for 2 hours with a heating rate of $5{ }^{\circ} \mathrm{C} \mathrm{min}^{-1}$ and then cooled to room temperature with a cooling rate of $10{ }^{\circ} \mathrm{C} \mathrm{min}{ }^{-1}$ to obtain $\mathrm{N}-\mathrm{CFs} / \mathrm{MoS}_{2}$ with $\mathrm{CMC}-\mathrm{NH}_{4}$ as carbon and nitrogen source. The preparation process is shown in Fig. 1.

For comparison, N-CFs were also prepared from CMC- $\mathrm{NH}_{4}$ by high temperature carbonization under the same conditions.

\section{Characterization}

The microstructure and morphology of the samples were conducted using a Hitachi S-4800 field-emission-gun scanning electron microscope (SEM) at $5 \mathrm{kV}$ and $15 \mathrm{kV}$ and a JEM-200CX transmission electron microscope (TEM). The chemical composition was performed by the energy dispersive X-ray spectroscopy (EDS). The high-resolution transmission electron microscopy (HRTEM) observations were investigated on Tecnai F20 TEM under $200 \mathrm{kV}$ acceleration voltage. X-ray diffraction (XRD) analysis was characterized with a Bruker AXS D8 Discover diffractometer (Germany) using $\mathrm{Cu}-\mathrm{K} \alpha$ radiation $(\lambda=1.5406 \AA)$ and the $2 \theta$ used in the measurements was range from 5 to $90^{\circ}$. Fourier transform infrared spectroscopy (FT-IR) was measured with a Magna-IR 750 spectrophotometer. X-ray photoelectron spectroscopy (XPS) of the samples were characterized with a PHI 5300 Photoelectron Spectrometer (Perkin Elmer Instruments Co. Ltd., USA). Thermogravimetric analysis (TG-DTA 6200 LAB SYS) was carried out in air from 50 to $800{ }^{\circ} \mathrm{C}$ at a heating rate of $10{ }^{\circ} \mathrm{C} \min ^{-1}$.

\section{Electrochemical measurements}

The electrochemical properties of the as-synthesized N-CFs/ $\mathrm{MoS}_{2}$ hybrids, $\mathrm{MoS}_{2}$ and N-CFs were investigated on an electrochemical workstation (on a CHI 660D, CH Instruments, Inc). PVDF was added to NMP and magnetically stirred until it was completely dissolved and the mixture turned transparent. The concentration of the PVDF/NMP solution was $0.01 \mathrm{~g} \mathrm{~mL}^{-1}$. The as-synthesized three materials were each ground in an agate mortar and mixed with acetylene black and the PVDF/NMP solutions by magnetic stirring until uniformly mixed. The mass ratio of electroactive material to acetylene black and PVDF was $8: 1: 1$. The mixture was then evenly coated onto a Ni foam current collector $(1 \mathrm{~cm} \times 3 \mathrm{~cm})$ and the coating area measured $1 \times 1 \mathrm{~cm}^{2}$. The electrode was dried in an oven at $60{ }^{\circ} \mathrm{C}$ for $18 \mathrm{~h}$ until all the NMP was evaporated, after which the Ni foam coated with the electrode material was pressed into thin sheet. For the three-electrode system tests, the thin Ni foam sheet with electrode material was used as a working electrode. Pt and Ag/ $\mathrm{AgCl}$ were used as counter and reference electrodes, respectively. The electrode clips were respectively clamped on the corresponding working, counter, and reference electrodes for electrochemical testing and a $\mathrm{KOH}$ aqueous solution (6 M) was used as an electrolyte. For the two-electrode system, two identically sized electrode sheets were used as symmetrical electrodes tested in the $6 \mathrm{M} \mathrm{KOH}$ electrolyte.

The cyclic voltammograms (CV) were performed at scan rates of $10,20,50,100,200$ and $400 \mathrm{mV} \mathrm{s}^{-1}$ with a potential range of -0.9 to $0.1 \mathrm{~V}$. The galvanostatic charge-discharge (GCD) properties were recorded in a potential window of -0.9 to $0.1 \mathrm{~V}$ at the current densities of $0.75,1.5,2.5,5$ and $10 \mathrm{~A} \mathrm{~g}^{-1}$. The electrochemical impedance spectroscopy (EIS) was assessed using a sinusoidal signal of $5 \mathrm{mV}$ within the frequency range of $0.01 \mathrm{~Hz}$ to $10^{5} \mathrm{~Hz}$ under open circuit potential. Cyclic stability was measured using GCD measurement for over 5000 cycles at the current density of $2.5 \mathrm{~A} \mathrm{~g}^{-1}$.

All the electrochemical parameters are calculated as follows, The gravimetric capacitance $\left(C_{\mathrm{g}}, \mathrm{F} \mathrm{g}^{-1}\right)$ :

$$
\begin{gathered}
C_{\mathrm{g}}=\left(\int i \mathrm{~d} V\right) /(v \times m \times V)(\mathrm{CV} \text { curves }) \\
\text { or } C_{\mathrm{g}}=I \times \Delta t /(\Delta V \times m)(\mathrm{GCD} \text { curves })
\end{gathered}
$$

where $v\left(\mathrm{mV} \mathrm{s}^{-1}\right)$ is the voltage scan rate, $V(\mathrm{~V})$ is the potential window, $m(\mathrm{~g})$ is the mass of the active substance, $I(\mathrm{~A})$ is the applied current, $\Delta t(\mathrm{~s})$ is the discharged time, $\Delta V(\mathrm{~V})$ is the discharged potential.

The energy density $\left(E, \mathrm{~W} \mathrm{~h} \mathrm{~kg}^{-1}\right)$ and power density $(P, \mathrm{~W}$ $\left.\mathrm{kg}^{-1}\right)$ :

$$
\begin{gathered}
E=1 / 2 \times C \times \Delta V^{2} \\
P=E / \Delta t
\end{gathered}
$$

where $C\left(\mathrm{~F} \mathrm{~g} \mathrm{~g}^{-1}\right)$ is the capacitance of the symmetric twoelectrode supercapacitor. $\Delta t(\mathrm{~h})$ is the discharged time, $\Delta V(\mathrm{~V})$ is the discharged potential.

\section{Results and discussion}

\section{Characterization of N-CFs/MoS $\mathbf{M o s}_{2}$ hybrid electrode materials}

Fig. 2 shows the scanning electron microscope (SEM) images of CMC-NH 4 , N-CFs and $\mathrm{MoS}_{2}$. The observed diameter of the intertwined cylindrical and ribbon-like $\mathrm{CMC}-\mathrm{NH}_{4}$ fibers, which 

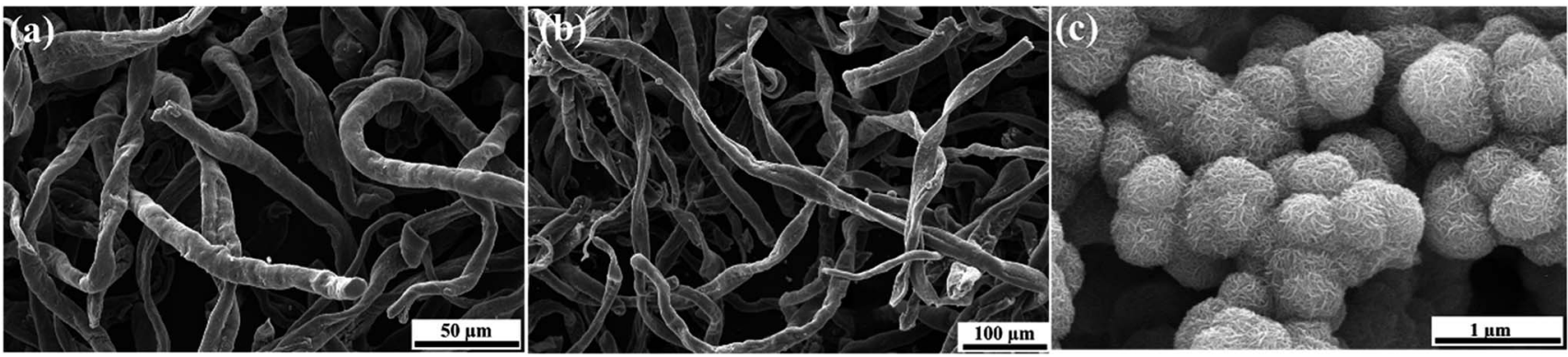

Fig. 2 SEM images of CMC-NH 4 (a), N-CFs (b), and $\mathrm{MoS}_{2}$ powder (c).

are several hundred micrometers in length as shown in Fig. 2a, is $10-15 \mu \mathrm{m}$. After water loss due to carbonization, almost all the N-CFs exhibit ribbon-like fibers with virtually no change in length (Fig. 2b). The SEM image of $\mathrm{MoS}_{2}$ powder prepared via hydrothermal synthesis is displayed in Fig. 2c. The $\mathrm{MoS}_{2}$ powder exhibits a relatively uniform and spherical shape with an average diameter of approximately $350 \mathrm{~nm}$. These spheres consisted of $\mathrm{MoS}_{2}$ nanosheets, indicating that the as-prepared $\mathrm{MoS}_{2}$ nanosheets would easily self-assemble into a flower-like structure.

The SEM images of CMC-NH ${ }_{4}$ and CMC-NH $\mathrm{N}_{4} / \mathrm{MoS}_{2}$ prepared via solvothermal synthesis under ethanol solutions with different concentrations are shown in Fig. $\mathrm{S} 1 \uparrow \cdot \mathrm{CMC}^{-\mathrm{NH}_{4}}$ is a polymer whose substituent group $\left(-\mathrm{CH}_{2} \mathrm{COONH}_{4}\right)$ is hydrophilic, so it is insoluble in anhydrous ethanol but readily soluble in water. Generally, polymers swell first and then dissolve in the dissolution process. They are normally composed of flexible chains that are easily curled into spherical shapes in solution. Therefore, after $\mathrm{CMC}-\mathrm{NH}_{4}$ is dissolved in water, treated hydrothermally, and washed with ethanol, its microscopic morphology changes from fibrous to a smooth spherical shape with a diameter of 1-5 $\mu \mathrm{m}$, as shown in Fig.S1a. $\uparrow$ Therefore, the $\mathrm{MoS}_{2}$ nanosheets are coated on the surface of the $\mathrm{CMC}^{-\mathrm{NH}_{4}}$ spheres (Fig. S1b $\dagger$ ) in the $\mathrm{CMC}-\mathrm{NH}_{4} / \mathrm{MoS}_{2}$ which is synthesized on the $\mathrm{CMC}^{-\mathrm{NH}_{4}}$ matrix in the aqueous medium, and the self-aggregation could not be prevented effectively. When the synthesis is conducted under ethanol solution with a concentration of $25 \%$, the rate of dissolution for CMC- $\mathrm{NH}_{4}$ is slightly lower than that in water. Therefore, CMC$\mathrm{NH}_{4}$ is not completely dissolved, and a small number of shortlength $\mathrm{CMC}-\mathrm{NH}_{4}$ fibers remained at the end of the reaction (Fig. S1c $\dagger$ ). Fig. S1d $\dagger$ shows the microscopic morphology of CMC-NH $\mathrm{N}_{4} / \mathrm{MoS}_{2}$ hybrids prepared via solvothermal synthesis in $25 \%$ ethanol solution. The $\mathrm{MoS}_{2}$ nanosheets are uniformly attached on the surface of $\mathrm{CMC}-\mathrm{NH}_{4}$ fibers that are not dissolved completely, while the remaining dissolved spherical CMC- $\mathrm{NH}_{4}$ are tightly coated by self-assembled $\mathrm{MoS}_{2}$ nanosheets. The self-agglomeration is still not effectively prevented. When the concentration of ethanol solution is further increased to $50 \%$, the dissolution rate of $\mathrm{CMC}^{-\mathrm{NH}_{4}}$ is even slower. The morphology of $\mathrm{CMC}-\mathrm{NH}_{4}$ still maintains its fibrous structure, but it changes from long-length fibers to short-length fibers and rods (Fig. S1e $\dagger$ ). The SEM image of the CMC-NH $\mathrm{N}_{4} / \mathrm{MoS}_{2}$ hybrids prepared under the same conditions is displayed in Fig. S1f. $\dagger$ Obviously, the $\mathrm{CMC}-\mathrm{NH}_{4}$ serves as a structure-directing agent for the growth of $\mathrm{MoS}_{2}$ nanosheets so that they are evenly grown on the surfaces of the CMC- $\mathrm{NH}_{4}$ fibers. Thus, the self-assembly agglomeration of $\mathrm{MoS}_{2}$ nanosheets is effectively avoided. Moreover, the CMC- $\mathrm{NH}_{4}$ is almost insoluble as the concentration of ethanol solution increased to $75 \%$, so the $\mathrm{CMC}^{-\mathrm{NH}_{4}}$ exhibits a fibrous structure almost similar to its initial morphology (Fig. S1g†). However, $\mathrm{MoS}_{2}$ nanosheets can only be formed when $\mathrm{Na}_{2} \mathrm{MoO}_{4} \cdot 2 \mathrm{H}_{2} \mathrm{O}$ and $\mathrm{L}$-cysteine react in aqueous solutions. The amount of water is not sufficient for the synthesis of $\mathrm{MoS}_{2}$ nanosheets in $75 \%$ ethanol solution. Consequently, only a small amount of $\mathrm{MoS}_{2}$ nanosheets are formed and sparsely adhered to the surface of $\mathrm{CMC}^{-\mathrm{NH}_{4}}$ fibers (Fig. S1h†). Furthermore, no $\mathrm{MoS}_{2}$ nanosheets are formed in anhydrous ethanol, in which the $\mathrm{CMC}-\mathrm{NH}_{4}$ is insoluble and $\mathrm{Na}_{2} \mathrm{MoO}_{4} \cdot 2 \mathrm{H}_{2} \mathrm{O}$ does not react with L-cysteine. Hence, only $\mathrm{CMC}-\mathrm{NH}_{4}$ fibers are observed in Fig. S1i and $\mathrm{j} . \dagger$

Fig. 3 shows magnified SEM images of $\mathrm{CMC}-\mathrm{NH}_{4} / \mathrm{MoS}_{2}$ hybrids prepared solvothermally in $50 \%$ ethanol solution, $\mathrm{N}$ $\mathrm{CFs} / \mathrm{MoS}_{2}$ hybrid electrode materials prepared by hightemperature carbonization, the EDS spectra, and the corresponding EDS mappings of elements. As shown in Fig. 3a, the CMC- $\mathrm{NH}_{4}$ successfully serves as the structure-directing agent for the growth of $\mathrm{MoS}_{2}$ nanosheets in 50\% ethanol solution. The as-synthesized $\mathrm{MoS}_{2}$ nanosheets are evenly grown on the surfaces of the $\mathrm{CMC}-\mathrm{NH}_{4}$ fibers, indicating that the $\mathrm{CMC}^{-\mathrm{NH}_{4}}$ successfully prevents the self-accumulation of $\mathrm{MoS}_{2}$ nanosheets during the synthesis process. After high-temperature carbonization, the $\mathrm{MoS}_{2}$ nanosheets are still uniformly attached on the surfaces of CMC-NH ${ }_{4}$ fibers (Fig. 3b). The EDS spectra (Fig. 3c) and mass percentage of the elements (Fig. $3 \mathrm{~h}$ ) further demonstrate the co-existence of the elements as follows: C (49.78\%), N (4.71\%), S (21.48\%), and Mo (24.03\%); and the $\mathrm{C}$ and $\mathrm{N}$ atoms are derived from N-CFs in N-CFs/ $/ \mathrm{MoS}_{2}$ obtained by hightemperature carbonization of $\mathrm{CMC}-\mathrm{NH}_{4} / \mathrm{MoS}_{2}$. In addition, the EDS mappings of elements shown in Fig. $3 \mathrm{~d}$-g provide more evidence for the co-existence of $\mathrm{C}, \mathrm{N}, \mathrm{S}$, and Mo atoms, respectively. This further confirms that $\mathrm{MoS}_{2}$ nanosheets are uniformly grown on the surfaces of $\mathrm{CMC}-\mathrm{NH}_{4}$ fibers. Moreover, the atomic percentages of S and Mo in N-CFs/ $\mathrm{MoS}_{2}$ electrode materials are $14.39 \%$ and $6.94 \%$, respectively, which is consistent with the molar ratio of $2: 1$ in $\mathrm{MoS}_{2}$. 

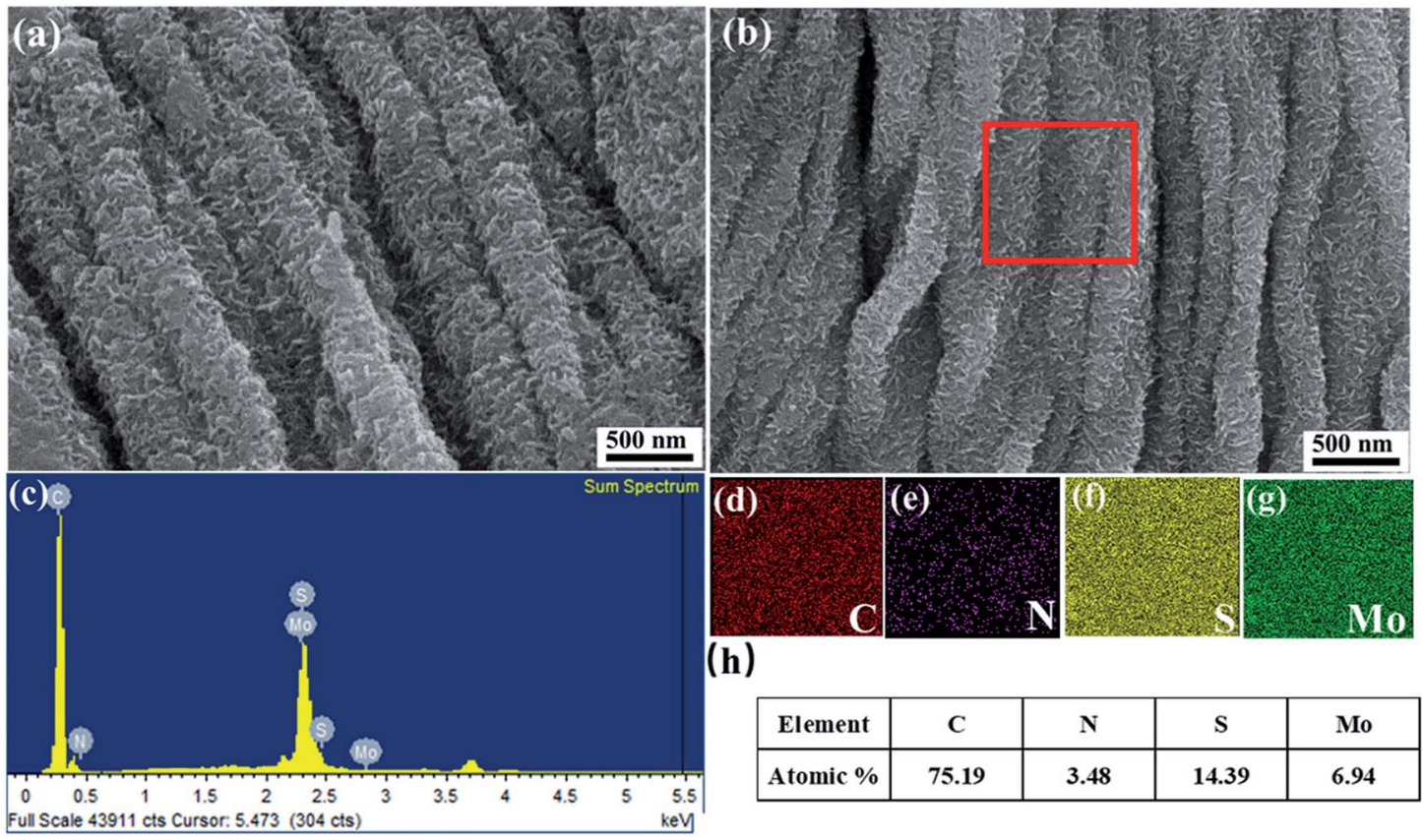

(h)

\begin{tabular}{|c|c|c|c|c|}
\hline Element & $\mathrm{C}$ & $\mathrm{N}$ & $\mathrm{S}$ & Mo \\
\hline Atomic \% & 75.19 & 3.48 & 14.39 & 6.94 \\
\hline
\end{tabular}

Fig. 3 SEM images of magnified view of (a) $C M C-N_{4} / M_{0} S_{2}$ hybrid materials, (b) N-CFs/MoS 2 hybrid electrode materials. (c) EDS spectra of the elements of $\mathrm{N}-\mathrm{CFs} / \mathrm{MoS}_{2}$ hybrid electrode materials, $(\mathrm{d}-\mathrm{g})$ The corresponding EDS elemental mappings of $\mathrm{N}-\mathrm{CFs} / \mathrm{MoS} 2$ hybrid electrode materials, (h) the weight percentages and atomic percentages of the elements.

The morphology of the $\mathrm{N}-\mathrm{CFs} / \mathrm{MoS}_{2}$ hybrid materials is further investigated by high resolution transmission electron microscopy (HRTEM). In Fig. 4a, five to eight layers of $\mathrm{MoS}_{2}$ nanosheets can be observed with a spacing of $0.63 \mathrm{~nm}$ which corresponds to the (002) lattice of hexagonal $\mathrm{MoS}_{2}$. Fig. $4 \mathrm{~b}$ shows selected-area electron diffraction (SAED) spectra of the $\mathrm{MoS}_{2}$. The diffraction rings correspond to the characteristic diffraction peaks of the (110), (103), (100), and (002) crystal planes of $\mathrm{MoS}_{2}$ respectively, which are consistent with the XRD pattern of $\mathrm{MoS}_{2}$.

The crystalline structures of the $\mathrm{CMC}^{-\mathrm{NH}_{4}}, \mathrm{MoS}_{2}, \mathrm{~N}-\mathrm{CFs}$, CMC-NH$H_{4} / \mathrm{MoS}_{2}$, and N-CFs/MoS 2 are characterized by X-ray diffraction (XRD) as shown in Fig. 5a. A sharp characteristic diffraction peak at a $2 \theta$ angle of $19.5^{\circ}$ is detected in the XRD pattern for $\mathrm{CMC}^{-\mathrm{NH}_{4}}$, corresponding to the (110) crystal plane of a typical cellulose II crystal structure. ${ }^{25}$ In the XRD pattern for pure $\mathrm{MoS}_{2}$ powder, the characteristic diffraction peaks at $2 \theta$ angles of $14^{\circ}$ and $59^{\circ}$ are assigned to the (002) and (110) crystal
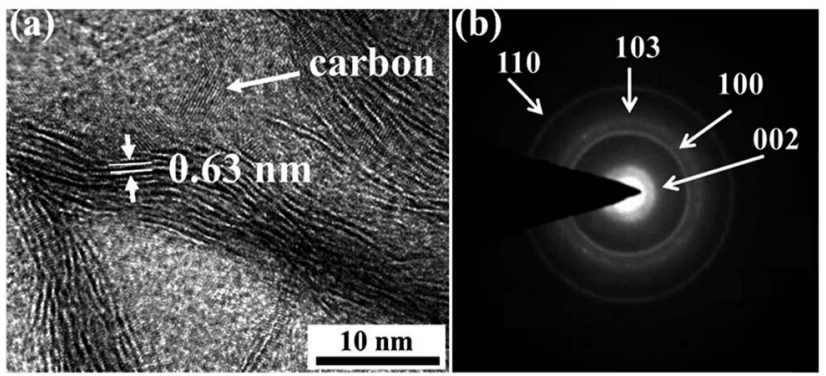

Fig. 4 The HRTEM image (a) and SAED pattern (b) of N-CFs/MoS 2 hybrid electrode materials. planes, respectively, whereas the stacked diffraction peaks around $2 \theta$ angles of $33-40^{\circ}$ are assigned to the (100) and (103) planes, respectively. ${ }^{26}$ The XRD pattern of $\mathrm{CMC}-\mathrm{NH}_{4} / \mathrm{MoS}_{2}$ exhibits characteristic diffraction peaks similar to those of CMC- $-\mathrm{NH}_{4}$ and $\mathrm{MoS}_{2}$, indicating that the $\mathrm{MoS}_{2}$ nanosheets are successfully grown on the surfaces of $\mathrm{CMC}^{-\mathrm{NH}_{4}}$ fibers. However, the characteristic diffraction peak at a $2 \theta$ angle of $19.5^{\circ}$ is weaker than that of the pure $\mathrm{CMC}^{-\mathrm{NH}_{4}}$. This is because part of the crystalline structure of $\mathrm{CMC}^{-\mathrm{NH}_{4}}$ is destroyed by water molecules during the solvothermal synthesis process, thus converting the long-length fibers to short-length fibers and rods. The XRD pattern of $\mathrm{N}-\mathrm{CFs} / \mathrm{MoS}_{2}$ shows the characteristic diffraction peaks of $\mathrm{MoS}_{2}$ and N-CFs. The peaks at a $2 \theta$ angle of $19.5^{\circ}$ disappeared completely for N-CFs/ $\mathrm{MoS}_{2}$ and N-CFs, while two new characteristic diffraction peaks are observed at $2 \theta$ angles of $24.6^{\circ}$ and $44^{\circ}$, which correspond to the (002) and (100) crystal planes of graphene, respectively, indicating that the $\mathrm{N}$ $\mathrm{CFs} / \mathrm{MoS}_{2}$ and N-CFs have a low degree of graphitization. ${ }^{27}$

The Fourier transform infrared spectroscopy (FTIR) spectra of pure $\mathrm{MoS}_{2}$ powder, CMC-NH$H_{4}, \mathrm{~N}-\mathrm{CFs}, \mathrm{CMC}-\mathrm{NH}_{4} / \mathrm{MoS}_{2}$, and $\mathrm{N}-\mathrm{CFs} / \mathrm{MoS}_{2}$ hybrids are shown in Fig. 5b. The weak peak at $590 \mathrm{~cm}^{-1}$ for pure $\mathrm{MoS}_{2}$ powder is attributed to the Mo-S vibrations. ${ }^{28}$ In the FTIR spectrum of $\mathrm{CMC}^{-\mathrm{NH}_{4}}$, the strong and broad absorption peak at $3399 \mathrm{~cm}^{-1}$ corresponds to its $\mathrm{O}-\mathrm{H}$ stretching vibrations, ${ }^{29}$ the characteristic absorption peak at $2919 \mathrm{~cm}^{-1}$ corresponds to the stretching vibrations of $\mathrm{C}-\mathrm{H}$, and the characteristic absorption peaks at 1604 and $1418 \mathrm{~cm}^{-1}$ are due to the vibrations of -COO- in the carboxylate groups. ${ }^{30}$ Moreover, the characteristic absorption peak at $1052 \mathrm{~cm}^{-1}$ is attributed to the stretching vibrations of $\mathrm{C}-\mathrm{O}-\mathrm{C}$, which proves the existence of ether linkage in six-membered rings. ${ }^{31}$ 

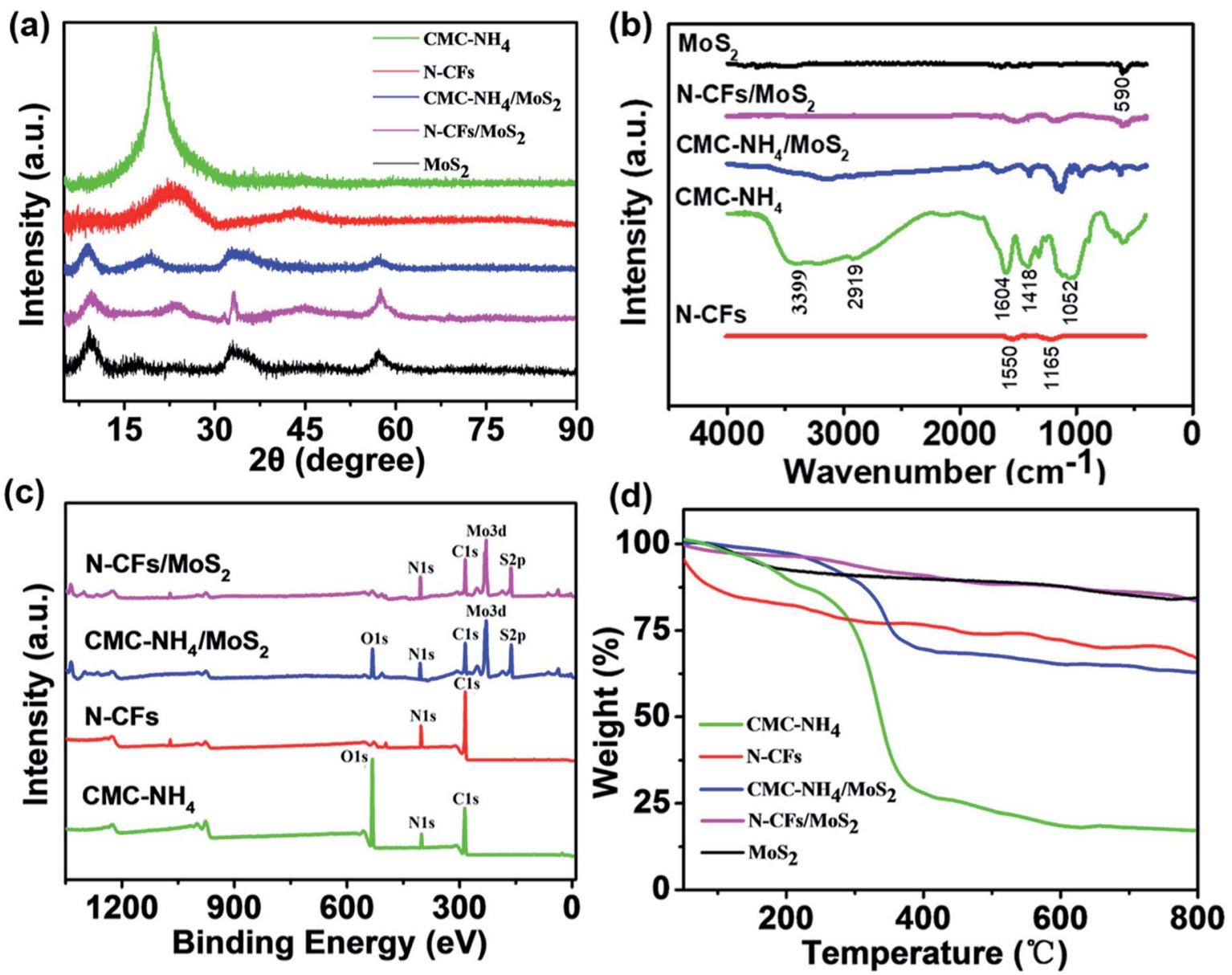

Fig. 5 XRD patterns (a), FT-IR (b), XPS (c) and TG (d) of samples.

Compared with $\mathrm{CMC}-\mathrm{NH}_{4}$, the characteristic absorption peaks of the above functional groups almost disappear in the FTIR spectra of N-CFs, while two new absorption peaks appear at 1550 and $1165 \mathrm{~cm}^{-1}$, which can be assigned to the characteristic absorption peaks of $C=\mathrm{N}$ and $\mathrm{C}-\mathrm{N}$ bonds, respectively. It is further proved that the $\mathrm{CMC}-\mathrm{NH}_{4}$ is successfully carbonized and nitrogen-doped. Additionally, the $\mathrm{CMC}-\mathrm{NH}_{4} / \mathrm{MoS}_{2}$ maintains the characteristic absorption peaks of CMC- $\mathrm{NH}_{4}$ and $\mathrm{MoS}_{2}$, and $\mathrm{N}-\mathrm{CFs} / \mathrm{MoS}_{2}$ contains the characteristic peaks of N-CFs and $\mathrm{MoS}_{2}$. These also confirm that the $\mathrm{MoS}_{2}$ nanosheets are successfully and evenly attached on the surfaces of $\mathrm{CMC}-\mathrm{NH}_{4}$ and N-CFs. Fig. 5c shows the X-ray photoelectron spectroscopy (XPS) spectra for the as-prepared samples. The characteristic absorption peaks of $\mathrm{O} 1 \mathrm{~s}, \mathrm{C} 1 \mathrm{~s}, \mathrm{~N} 1 \mathrm{~s}, \mathrm{~S} 2 \mathrm{p}$, and Mo $3 \mathrm{~d}$ are detected, while characteristic peaks for only C 1s, N 1s, S 2p, and Mo 3d are observed for $\mathrm{N}-\mathrm{CFs} / \mathrm{MoS}_{2}$ hybrid electrode material. This is also consistent with the EDS results shown in Fig. 3.

Fig. 5d shows the thermogravimetric analysis (TG) analysis graph for the as-prepared samples. Both physical and chemical changes are involved in the thermal decomposition process of $\mathrm{CMC}-\mathrm{NH}_{4}$, as shown in Fig. 5d. The slight weight loss from $50{ }^{\circ} \mathrm{C}$ to $220{ }^{\circ} \mathrm{C}$ is due to the evaporation of the physically absorbed water. There is a relative large weight loss in the range of $220-290{ }^{\circ} \mathrm{C}$, while a very large and rapid weight loss is detected in the range of $290-380{ }^{\circ} \mathrm{C}$ due to the decomposition of CMC- $\mathrm{NH}_{4}$. The weight loss is mainly caused by the removal of volatile gases generated from the decomposition of organic compounds. As the temperature continued to increase, the rate of weight loss gradually decreased, and a constant weight is obtained after $600{ }^{\circ} \mathrm{C}$ when only a small amount of sodium salts are the major residuals. The weight loss of N-CFs is also mainly caused by its decomposition, with a small quantity of sodium salts as residuals. However, the weight loss of $\mathrm{MoS}_{2}$ comes from the oxidation of $\mathrm{MoS}_{2}$ to $\mathrm{MoO}_{3}$ and $\mathrm{SO}_{2}$ when heated to $315^{\circ} \mathrm{C}$. Thus, the weight losses in $\mathrm{CMC}-\mathrm{NH}_{4} / \mathrm{MoS}_{2}$ and $\mathrm{N}-\mathrm{CFs} / \mathrm{MoS}_{2}$ are not only attributed to the decomposition of $\mathrm{CMC}^{-\mathrm{NH}_{4}}$ and $\mathrm{N}$ CFs substrates, but also to the oxidation reaction of $\mathrm{MoS}_{2}$. Therefore, the main residues are dominated by a small amount of sodium salts and $\mathrm{MoO}_{3}$.

The specific surface area and porous structure of the samples are characterized by measuring the $\mathrm{N}_{2}$ adsorption-desorption isotherms. It can be seen from the isotherm curves (Fig. S2a $\dagger$ ) and the pore size distribution (Fig. S2b $\dagger$ ), the samples of $\mathrm{MoS}_{2}$, CMC-NH ${ }_{4}, \mathrm{~N}-\mathrm{CFs}, \mathrm{CMC}-\mathrm{NH}_{4} / \mathrm{MoS}_{2}$ and $\mathrm{N}-\mathrm{CFs} / \mathrm{MoS}_{2}$ are mainly characteristic of micropores and mesoporous, and their specific surface areas are in order of $9.3 \mathrm{~m}^{2} \mathrm{~g}^{-1}, 14.73 \mathrm{~m}^{2} \mathrm{~g}^{-1}$, $18.76 \mathrm{~m}^{2} \mathrm{~g}^{-1}, 40.47 \mathrm{~m}^{2} \mathrm{~g}^{-1}, 32.78 \mathrm{~m}^{2} \mathrm{~g}^{-1}$. These results demonstrate the addition of the $\mathrm{CMC}-\mathrm{NH}_{4}$ effectively prevents 
the agglomeration of $\mathrm{MoS}_{2}$ nanosheets during the solvothermal synthesis of $\mathrm{MoS}_{2}$ and thus increasing the specific surface area.

\section{Electrochemical characteristics of N-CFs/MoS 2 hybrid electrode materials}

The N-CFs/ $\mathrm{MoS}_{2}$ hybrids prepared above are then evaluated as an electrode material for supercapacitors. For comparison, the electrochemical performance of pure $\mathrm{MoS}_{2}$ and N-CFs are also tested. All tests are conducted under room-temperature conditions.

Fig. 6a shows the cyclic voltammograms (CV) curves of the pure $\mathrm{MoS}_{2}, \mathrm{~N}-\mathrm{CFs}$, and N-CFs/MoS 2 hybrids at a scan rate of $50 \mathrm{mV} \mathrm{s}^{-1}$ with a potential window range of -0.9 to $0.1 \mathrm{~V}$. All the CV curves exhibit a nearly symmetrical rectangular shape, indicating ideal capacitive behaviors of the three materials. The difference is the $\mathrm{N}-\mathrm{CFs} / \mathrm{MoS}_{2}$ hybrids display a much higher capacitance than the other two for the larger CV enclosed area which can also be demonstrated by a longer discharge time in the GCD curves at a current density of $2.5 \mathrm{~A} \mathrm{~g}^{-1}$ with voltage between -0.9 and $0.1 \mathrm{~V}$ (Fig. 6c). Fig. 6b exhibits the CV curves of the N-CFs/ $\mathrm{MoS}_{2}$ hybrids at scan rates of 10 to $400 \mathrm{mV} \mathrm{s}^{-1}$. As can be seen from the figure, even the scan rate is increased to $400 \mathrm{mV} \mathrm{s}^{-1}$, the CV curve still maintains an almost symmetrical rectangular shape without significant deformation. This provides evidence for the N-CFs/MoS ${ }_{2}$ hybrids' fast response to current when the voltage reverses. Furthermore, the specific capacitance $\left(C_{\mathrm{g}}\right)$ of the $\mathrm{N}-\mathrm{CFs} / \mathrm{MoS}_{2}$ hybrids calculated from the $\mathrm{CV}$ curve at a scan rate of $10 \mathrm{mV} \mathrm{s}^{-1}$ is $588.5 \mathrm{~F} \mathrm{~g}^{-1}$, which is higher than those reported in the literature for $\mathrm{MoS}_{2} / \mathrm{C}$ based electrodes, such as CF@MoS nanocomposites synthesized by
Liu et al. $\left(503.7 \mathrm{~F} \mathrm{~g}^{-1}\right.$ at a scan rate of $50 \mathrm{mV} \mathrm{s}{ }^{-1}$ in $1 \mathrm{M} \mathrm{Na}_{2} \mathrm{SO}_{4}$ aqueous electrolyte), ${ }^{21}$ and porous tubular $\mathrm{C} / \mathrm{MoS}_{2}$ nanocomposites by $\mathrm{Hu}$ et al. (210 $\mathrm{F} \mathrm{g}^{-1}$ at a current density of $\left.1 \mathrm{~A} \mathrm{~g}^{-1}\right) .{ }^{32}$ Moreover, it is higher than other $\mathrm{MoS}_{2}$-based hybrids, such as $\mathrm{MoS}_{2} / \mathrm{RGO}\left(148 \mathrm{~F} \mathrm{~g}^{-1}\right.$ at a scan rate of $\left.10 \mathrm{mV} \mathrm{s}^{-1}\right),{ }^{19}$ and $\mathrm{MoS}_{2} /$ PANI (575 $\mathrm{F} \mathrm{g}^{-1}$ at a current density of $1 \mathrm{~A} \mathrm{~g}^{-1}$ ). ${ }^{20}$

Fig. 6d displays the galvanostatic charge-discharge (GCD) curves of the $\mathrm{N}-\mathrm{CFs} / \mathrm{MoS}_{2}$ hybrid electrode materials under different current densities $\left(0.75,1.5,2.5,5\right.$, and $\left.10 \mathrm{~A} \mathrm{~g}^{-1}\right)$. An almost symmetrical triangular shape is observed in all of the charge-discharge curves in the designated potential range, indicating that the $\mathrm{N}-\mathrm{CF} / \mathrm{MoS}_{2}$ hybrids exhibit excellent capacitance performance and fast current-voltage response. ${ }^{33}$ Fig. 6e presents the $C_{\mathrm{g}}$ of the three materials which are calculated from the discharge curves at various current densities. As can be clearly seen from the figure, the $C_{\mathrm{g}}$ of the N-CFs/MoS hybrids are higher than the $C_{\mathrm{g}}$ of the other two at the same current density. And under a current density of $0.75 \mathrm{~A} \mathrm{~g}^{-1}$, the $C_{\mathrm{g}}$ of N-CFs/MoS $/ \mathrm{Mob}_{2}$ hybids, pure $\mathrm{MoS}_{2}$ and N-CFs are $572.6 \mathrm{~F} \mathrm{~g}^{-1}$, 198.7 $\mathrm{F} \mathrm{g}^{-1}$ and $178.6 \mathrm{~F} \mathrm{~g}^{-1}$, respectively. In addition, the $C_{\mathrm{g}}$ of them are maintained up to $456.4 \mathrm{~F} \mathrm{~g}^{-1}, 125.2 \mathrm{~F} \mathrm{~g}^{-1}$ and $121.1 \mathrm{~F} \mathrm{~g}^{-1}$ in order, which are $79.7 \%, 63.0 \%$ and $67.8 \%$ of the initial $C_{\mathrm{g}}$ even when the current density is increased to $10 \mathrm{~A} \mathrm{~g}^{-1}$. This illuminates the excellent capacitance retention property of the N-CFs/ $\mathrm{MoS}_{2}$ hybrids when working as an electrode material. Furthermore, for the large volume change and poor electrical/ ionic conductivity between the two adjacent S-Mo-S sheets of $\mathrm{MoS}_{2}$ (ref. 16-18) and the introduction of nitrogen atoms to the carbonized $\mathrm{CMC}-\mathrm{NH}_{4}$, the N-CFs has a higher capacitance retention than $\mathrm{MoS}_{2}$.
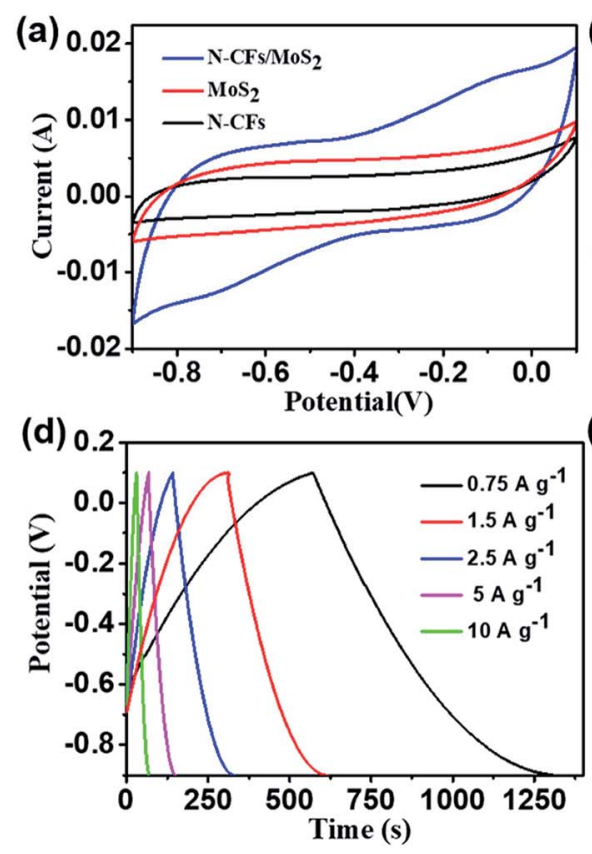

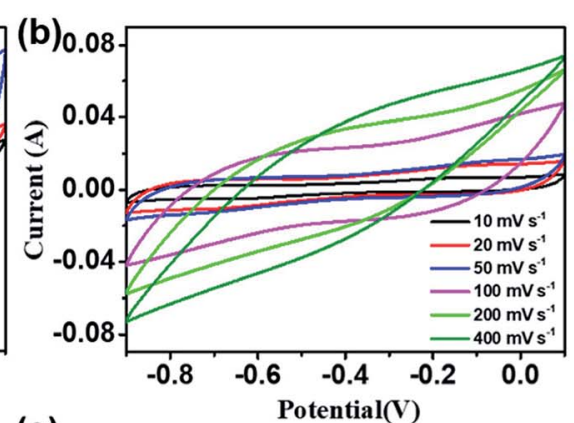

(e)

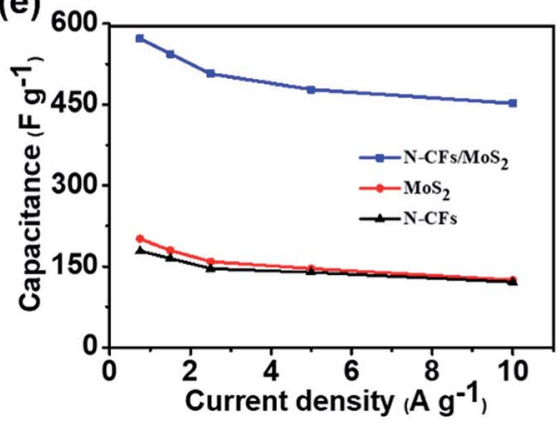

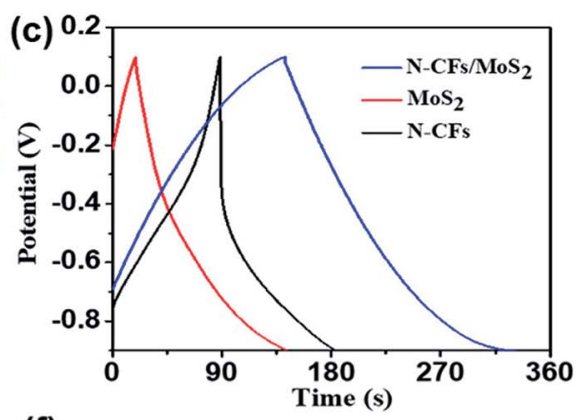

(f)

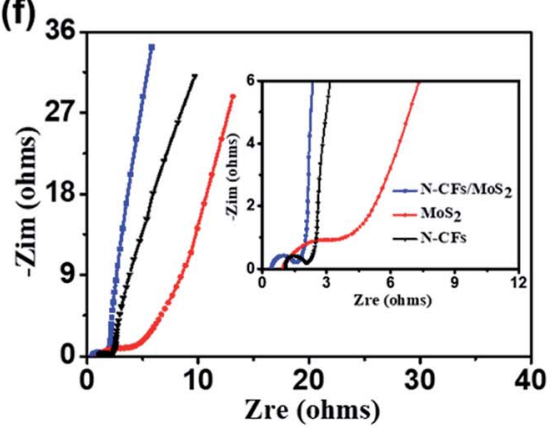

Fig. 6 (a) Typical CV curves of the N-CFs/MoS 2 hybrid electrode materials, $\mathrm{MoS}_{2}$ and N-CFs at a scan rate of $50 \mathrm{mV} \mathrm{s}{ }^{-1}$. (b) Typical CV curves of the N-CFs/MoS 2 hybrid electrode materials at different scan rates. (c) Typical GCD curves of the N-CFs/MoS 2 hybrid electrode materials, MoS 2 and N-CFs at a current density of $2.5 \mathrm{~A} \mathrm{~g}^{-1}$. (d) Typical GCD curves of the N-CFs/MoS 2 hybrid electrode materials at different current densities. (e) The specific capacitance of the N-CFs/MoS 2 hybrid electrode materials, $\mathrm{MoS}_{2}$ and $\mathrm{N}-\mathrm{CFs}$ as a function of the current density. (f) Nyquist impedance plots of the N-CFs/MoS 2 hybrid electrode materials, $\mathrm{MoS}_{2}$ and N-CFs. Inset is a magnified view of the high frequency region. 
The electrochemical impedance spectroscopy (EIS) is one of the most important methods for investigating the electrochemical behavior of electrodes and excellent electrode materials should possess high capacitance and low resistance. ${ }^{34}$ Fig. $6 \mathrm{f}$ shows the Nyquist impedance spectra of the three materials at a frequency of $0.01 \mathrm{~Hz}$ to $100 \mathrm{kHz}$ under opencircuit voltage. As shown in the Fig. 6f, in the low-frequency region, the Nyquist plots display straight and almost vertical lines, indicating that the three materials exhibit ideal capacitance behaviors. ${ }^{35}$ The diffusion process of electrolyte ions in the electrode material can be evaluated in the mid-frequency region from the projected length of the Warburg curve with a slope of $45^{\circ}$ on the real axis. ${ }^{36}$ As displayed in the figure, the Warburg-type line of N-CFs/ $\mathrm{MoS}_{2}$ hybrids is relatively shorter than that of the other two, demonstrating the electrolyte ions diffuse faster in the N-CFs/MoS 2 hybrid materials. This is because the N-CFs in the hybrid materials not only provides conductive pathways, but also improves the conductivity of the electrodes, thus promoting the diffusion of electrons and ions. In the high-frequency region, the equivalent series resistance $\left(R_{\mathrm{ESR}}\right)$ values can be obtained from the real axis intersection of the Nyquist plots as presented in the inset of Fig. $6 f$. The value of N-CFs $/ \mathrm{MoS}_{2}$ hybrid materials is only $0.42 \Omega$, lower than the values of N-CFs and pure $\mathrm{MoS}_{2}$ which are $1.1 \Omega$ and $0.9 \Omega$, respectively. In addition, from the absence of semicircles (due to the charge transfer resistance) of the Nyquist plots, the $\mathrm{N}$ $\mathrm{CFs} / \mathrm{MoS}_{2}$ hybrid materials display lower charge transfer resistance than the other two materials. Thus, the N-CFs/MoS hybrid materials possess excellent ion-migration ability as an electrode material.

The cyclic stability is also an important feature of electrodes. The Fig. 7 shows the decay of the specific capacitance of the N$\mathrm{CFs} / \mathrm{MoS}_{2}$ hybrids for 5000 cycles of galvanostatic chargedischarge tests at a current density of $2.5 \mathrm{~A} \mathrm{~g}^{-1}$. After cycles, the specific capacitance of the $\mathrm{N}-\mathrm{CFs} / \mathrm{MoS}_{2}$ hybrids is $561.8 \mathrm{~F} \mathrm{~g}^{-1}$, which is $98 \%$ of the initial specific capacitance, indicating the outstanding electrochemical cyclic stability of the N-CFs/MoS hybrids as an electrode material.

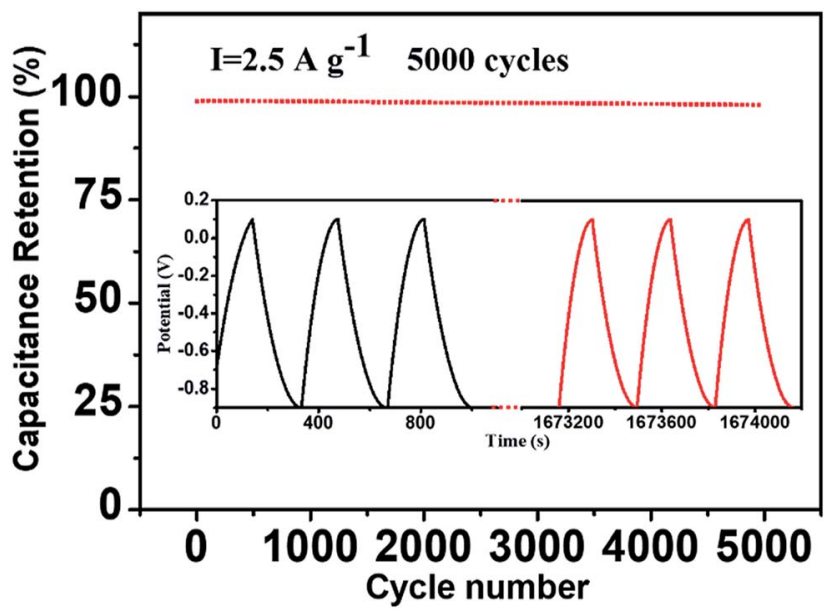

Fig. 7 Cycling stability of the $\mathrm{N}-\mathrm{CFs} / \mathrm{MoS}_{2}$ hybrid electrode materials over 5000 cycles at the current density of $2.5 \mathrm{~A} \mathrm{~g}^{-1}$, the inset is the galvanostatic charge-discharge curves.

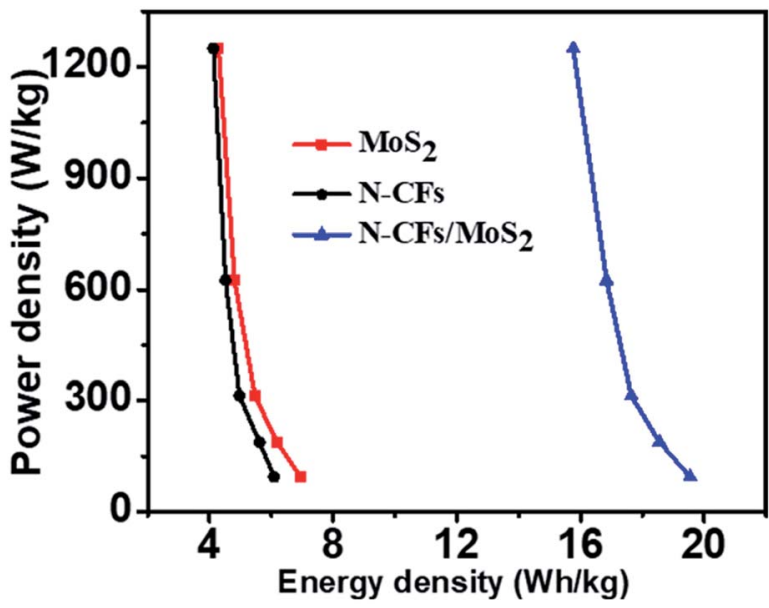

Fig. 8 Ragone plots (energy density vs. power density) of the $\mathrm{MoS}_{2}, \mathrm{~N}$ CFs, and N-CFs/MoS 2 hybrids based symmetric supercapacitors.

The energy and power densities are also calculated due to the two parameters are important as well for evaluating the electrochemical performance of supercapacitors. Fig. S3 $\uparrow$ is GCD curves and $C_{\mathrm{g}}$ of the pure $\mathrm{MoS}_{2}, \mathrm{~N}-\mathrm{CFs}$, and N-CFs/MoS $\mathrm{Mos}_{2}$ hybids based symmetric supercapacitors at different current densities. Fig. 8 presents the Ragone plots corresponding to the relationship between energy density and power density for the hybrids-based symmetric supercapacitors. It can be seen from the figure, as the power density increases from 94 to $1250 \mathrm{~W} \mathrm{~kg}^{-1}$, the energy densities of N-CFs and $\mathrm{MoS}_{2}$ decrease from 6.1 and $6.9 \mathrm{~W} \mathrm{~h} \mathrm{~kg}^{-1}$ to 4.1 and $4.3 \mathrm{~W} \mathrm{~h} \mathrm{~kg}^{-1}$, respectively. Comparatively, the N-CFs/MoS hybrids show energy density of $19.5 \mathrm{~W} \mathrm{~h} \mathrm{~kg}^{-1}$ at a power density of $94 \mathrm{~W} \mathrm{~kg}^{-1}$, and still retain $15.8 \mathrm{~W} \mathrm{~h} \mathrm{~kg}^{-1}$ at a power density of $1250 \mathrm{~W} \mathrm{~kg}{ }^{-1}$. These results illustrate the $\mathrm{N}-\mathrm{CFs} / \mathrm{MoS}_{2}$ hybrid electrode materials have higher energy density and power output.

The excellent electrochemical properties of the N-CFs/MoS hybrids as electrode materials are mainly attributed to the following two aspects. First, $\mathrm{CMC}-\mathrm{NH}_{4}$ serves as a structuredirecting agent during the solvothermal synthesis of $\mathrm{MoS}_{2}$, which effectively prevents the agglomeration of $\mathrm{MoS}_{2}$ nanosheets. In addition, the $\mathrm{MoS}_{2}$ nanosheets are evenly grown on the surfaces of $\mathrm{CMC}^{-\mathrm{NH}_{4}}$ thus increasing the specific surface area and providing large numbers of active sites for electrochemical reactions, so that the electrolyte and electrode materials can fully contact with each other to reduce the distance for ion diffusion. Second, using the CMC- $\mathrm{NH}_{4}$ as a carbon source to obtain the N-CFs via high-temperature carbonization not only provide conductive pathways, but also introduce $\mathrm{N}$ atoms that would effectively improve the electron-donating ability of the CFs, lower the valence orbital energy, improve the conductivity of the CFs, and promote the transfer of electrons and ions. This ultimately increases the conductivity of the electrode materials. Consequently, the as-prepared $\mathrm{N}-\mathrm{CFs} / \mathrm{MoS}_{2}$ hybrids exhibit remarkable electrochemical performance as electrode materials.

\section{Conclusions}

Novel N-CFs/MoS 2 hybrid materials were prepared via solvothermal synthesis in $50 \%$ ethanol solution followed by a high- 
temperature carbonization process, using $\mathrm{CMC}-\mathrm{NH}_{4}$ as a structure-directing agent in the solvothermal synthesis of $\mathrm{MoS}_{2}$ nanosheets. The as-prepared $\mathrm{N}-\mathrm{CFs} / \mathrm{MoS}_{2}$ hybrid electrode materials exhibit excellent electrochemical performance. The measured specific capacitance is up to $572.6 \mathrm{~F} \mathrm{~g} \mathrm{~g}^{-1}$ at current density of $0.75 \mathrm{~A} \mathrm{~g}^{-1}$. Additionally, the $\mathrm{N}-\mathrm{CFs} / \mathrm{MoS}_{2}$ hybrids show high rate capability and great electrochemical cyclic stability that the specific capacitance retained $98 \%$ of the initial capacitance after 5000 cycles of charge-discharge tests at a current density of $2.5 \mathrm{~A} \mathrm{~g}^{-1}$. In addition, the hybrids display a maximum energy density of $19.5 \mathrm{~W} \mathrm{~h} \mathrm{~kg}{ }^{-1}$ at a power density of $94 \mathrm{~W} \mathrm{~kg}^{-1}$. Therefore, due to the excellent electrochemical properties, low cost, and environmental friendliness, the N-CFs/ $\mathrm{MoS}_{2}$ hybrids show potential for application in the energy field.

\section{Conflicts of interest}

There are no conflicts to declare.

\section{Acknowledgements}

We are grateful for the support of the Beijing Engineering Research Center of Cellulose and Its Derivatives.

\section{Notes and references}

1 D. Zhu, Y. Wang, W. Lu, H. Zhang, Z. Song, D. Luo, L. Gan, M. Liu and D. Sun, Carbon, 2017, 111, 667-674.

2 Y. Yang, F. Yang, H. Hu, S. Lee, Y. Wang, H. Zhao, D. Zeng, B. Zhou and S. Hao, Chem. Eng. J., 2017, 307, 583-592.

3 M. Liu, X. Wang, D. Zhu, L. Li, H. Duan, Z. Xu, Z. Wang and L. Gan, Chem. Eng. J., 2017, 308, 240-247.

4 C. Wang, J. Xu, M.-F. Yuen, J. Zhang, Y. Li, X. Chen and W. Zhang, Adv. Funct. Mater., 2014, 24, 6372-6380.

5 M. X. Liu, X. M. Ma, L. H. Gan, Z. J. Xu, D. Z. Zhu and L. W. Chen, J. Mater. Chem. A, 2014, 2, 17107-17114.

6 I. Oh, M. Kim and J. Kim, Chem. Eng. J., 2015, 273, 82-91.

7 X. Zhu, H. Dai, J. Hu, L. Ding and L. Jiang, J. Power Sources, 2012, 203, 243-249.

8 Y.-H. Lin, T.-Y. Wei, H.-C. Chien and S.-Y. Lu, Adv. Energy Mater., 2011, 1, 901-907.

9 W. Lu, M. Liu, L. Miao, D. Zhu, X. Wang, H. Duan, Z. Wang, L. Li, Z. Xu, L. Gan and L. Chen, Electrochim. Acta, 2016, 205, 132-141.

10 D. Zhu, Y. Wang, L. Gan, M. Liu, K. Cheng, Y. Zhao, X. Deng and D. Sun, Electrochim. Acta, 2015, 158, 166-174.

11 X. Yang, J. Zhu, L. Qiu and D. Li, Adv. Mater., 2011, 23, 28332838.

12 C. X. Guo and C. M. Li, Energy Environ. Sci., 2011, 4, 4504.

13 B. Xu, S. Yue, Z. Sui, X. Zhang, S. Hou, G. Cao and Y. Yang, Energy Environ. Sci., 2011, 4, 2826-2830.
14 M. Pumera, Z. Sofer and A. Ambrosi, J. Mater. Chem. A, 2014, 2, 8981-8987.

15 M.-R. Gao, Y.-F. Xu, J. Jiang and S.-H. Yu, Chem. Soc. Rev., 2013, 42, 2986-3017.

16 Q. Sun, Q.-Q. Ren, H. Li and Z.-W. Fu, Electrochem. Commun., 2011, 13, 1462-1464.

17 D. Su, S. Dou and G. Wang, Chem. Commun., 2014, 50, 41924195.

18 Y. Sun, X. Hu, W. Luo and Y. Huang, ACS Nano, 2011, 5, 7100-7107.

19 E. G. d. S. Firmiano, C. J. Dalmaschio, A. N. Pinheiro, E. C. Pereira, W. H. Schreiner and E. R. Leite, Adv. Energy Mater., 2014, 4, 1301380.

20 K.-J. Huang, L. Wang, Y.-J. Liu, H.-B. Wang, Y.-M. Liu and L.-L. Wang, Electrochim. Acta, 2013, 109, 587-594.

21 X. Liu, K. Liu, W. Zhou, L. Li, K. Zhou and S. Chen, Sci. Adv. Mater., 2015, 7, 2336-2342.

22 Y. Y. Lv, L. Li, Y. Zhou, M. Yu, J. Q. Wang, J. X. Liu, J. G. Zhou, Z. Q. Fan and Z. Q. Shao, RSC Adv., 2017, 7, 43512-43520.

23 W. Li, R. Wang and S. X. Liu, Prog. Chem., 2010, 22, 20602070.

24 J. Yamashita, T. Ojima, M. Shioya, H. Hatori and Y. Yamada, Carbon, 2003, 41, 285-294.

25 Y. Yang, Z. Tong, T. Ngai and C. Wang, ACS Appl. Mater. Interfaces, 2014, 6, 6351-6360.

26 A. G. A. Di Fabio, M. Mastragostino and F. Soavi, J. Electrochem. Soc., 2001, 148, A845-A850.

27 H. R. Nie, M. Z. Liu, F. L. Zhan and M. Y. Guo, Carbohydr. Polym., 2004, 58, 185-189.

28 S. Liu, X. Zhang, H. Shao, J. Xu, F. Chen and Y. Feng, Mater. Lett., 2012, 73, 223-225.

29 X. Wu and W. Jia, Chem. Eng. J., 2014, 245, 210-216.

30 M. Xu, Y. Ao, S. Wang, J. Peng, J. Li and M. Zhai, Carbohydr. Polym., 2015, 128, 171-178.

31 E. Y. L. Teo, L. Muniandy, E.-P. Ng, F. Adam, A. R. Mohamed, R. Jose and K. F. Chong, Electrochim. Acta, 2016, 192, 110119.

32 B. L. Hu, X. Y. Qin, A. M. Asiri, K. A. Alamry, A. O. Al-Youbi and X. P. Sun, Electrochim. Acta, 2013, 100, 24-28.

33 X. Wang, X. Wang, L. Yi, L. Liu, Y. Dai and H. Wu, J. Power Sources, 2013, 224, 317-323.

34 A. Di Fabio, A. Giorgi, M. Mastragostino and F. Soavi, J. Electrochem. Soc., 2001, 148, A845-A850.

35 J. Yan, J. P. Liu, Z. J. Fan, T. Wei and L. J. Zhang, Carbon, 2012, 50, 2179-2188.

36 W. Shi, J. Zhu, D. H. Sim, Y. Y. Tay, Z. Lu, X. Zhang, Y. Sharma, M. Srinivasan, H. Zhang, H. H. Hng and Q. Yan, J. Mater. Chem., 2011, 21, 3422. 